\title{
The Quest for Anti-inflammatory and Anti-infective Biomaterials in Clinical Translation
}

\author{
May Griffith ${ }^{1,2,3}$, Mohammad M. Islam ${ }^{1,2}$, Joel Edin ${ }^{1,2}$, Georgia Papapavlou', \\ Oleksiy Buznyk ${ }^{4}$ and Hirak K. Patra ${ }^{1 *}$
}

\begin{abstract}
'Department of Clinical and Experimental Medicine (IKE), Linköping University, Linköping, Sweden, ${ }^{2}$ Department of Neuroscience, Swedish Medical Nanoscience Center, Karolinska Institutet, Stockholm, Sweden, ${ }^{3}$ Department of Ophthalmology, Maisonneuve-Rosemont Hospital Research Center, University of Montreal, Montreal, QC, Canada, ${ }^{4}$ Department of Eye Burns, Ophthalmic Reconstructive Surgery, Keratoplasty and Keratoprosthesis, Filatov Institute of Eye diseases and Tissue Therapy of the NAMS of Ukraine, Odessa, Ukraine
\end{abstract}

\section{OPEN ACCESS}

Edited by: Alejandro Dario Sosnik, Technion - Israel Institute of Technology, Israel

Reviewed by: Ahmed El-Fiqi,

Dankook University, South Korea Brendan M. Leung, Dalhousie University, Canada

*Correspondence: Hirak K. Patra hirak.kumar.patra@liu.se

Specialty section:

This article was submitted to Biomaterials,

a section of the journal Frontiers in Bioengineering and Biotechnology

Received: 02 June 2016 Accepted: 26 August 2016 Published: 09 September 2016

Citation:

Griffith M, Islam MM, Edin J, Papapavlou G, Buznyk O and Patra HK (2016) The Quest for Anti-inflammatory and Anti-infective Biomaterials in Clinical Translation. Front. Bioeng. Biotechnol. 4:71. doi: 10.3389/fbioe.2016.00071
Biomaterials are now being used or evaluated clinically as implants to supplement the severe shortage of available human donor organs. To date, however, such implants have mainly been developed as scaffolds to promote the regeneration of failing organs due to old age or congenital malformations. In the real world, however, infection or immunological issues often compromise patients. For example, bacterial and viral infections can result in uncontrolled immunopathological damage and lead to organ failure. Hence, there is a need for biomaterials and implants that not only promote regeneration but also address issues that are specific to compromised patients, such as infection and inflammation. Different strategies are needed to address the regeneration of organs that have been damaged by infection or inflammation for successful clinical translation. Therefore, the real quest is for multifunctional biomaterials with combined properties that can combat infections, modulate inflammation, and promote regeneration at the same time. These strategies will necessitate the inclusion of methodologies for management of the cellular and signaling components elicited within the local microenvironment. In the development of such biomaterials, strategies range from the inclusion of materials that have intrinsic anti-inflammatory properties, such as the synthetic lipid polymer, 2-methacryloyloxyethyl phosphorylcholine (MPC), to silver nanoparticles that have antibacterial properties, to inclusion of nano- and micro-particles in biomaterials composites that deliver active drugs. In this present review, we present examples of both kinds of materials in each group along with their pros and cons. Thus, as a promising next generation strategy to aid or replace tissue/organ transplantation, an integrated smart programmable platform is needed for regenerative medicine applications to create and/or restore normal function at the cell and tissue levels. Therefore, now it is of utmost importance to develop integrative biomaterials based on multifunctional biopolymers and nanosystem for their practical and successful clinical translation.

Keywords: biomaterials, clinical translation, anti-inflammatory, anti-infective 


\section{INTRODUCTION}

Transplantation with donor organs or tissues is often the only treatment available for patients with end-stage organ damage leading to failure. However, the demand for donor organs is manyfold higher than the supply of donated organs. According to US Department of Health and Human Service, an average of 79 people receive organ transplants each day while 22 others die while waiting to be transplanted, due to the acute shortage of high quality-donated organs. ${ }^{1}$ Even if donor organs are available, problems such as graft-versus-host disease and rejection leading to graft failure still need to be solved. An alternative to donor organ transplantation is use of bioengineered artificial organs or multicomponent tissues as replacements. Tissue engineering and regenerative medicine are, therefore, rapidly growing areas (Stock and Vacanti, 2001).

In many cases, organ failure is due to congenital defects or aging. However, infections caused by viruses and bacteria can cause uncontrolled damage leading to organ failure. Current examples include pandemics such as the severe acute respiratory syndrome (SARS) that broke out in 2003. SARS was caused by a coronavirus and patients who died were otherwise healthy young adults whose immune system mounted an inflammatory response resulting in the destruction of pulmonary stem cells that led to death of the patients (Holmes, 2003). Even in the common influenza, in severe cases, upregulation of matrix metalloproteinase (MMP)-9 has been shown to result in tissue destruction in various organs (Wang et al., 2010). Bacterial infections often progress in a slower manner than viral ones. One area where bacterial infections are particularly problematic is in chronic skin wounds, such as non-healing ulcers and skin burns. In the eye, ulcers and burns along with infections are also a source of inflammation and tissue destruction. Whether the infections and ensuing immunopathological mechanisms that are triggered cause acute and rapid organ destruction or chronic problems, these are considerations in the development of biomaterials as scaffolds or implants that are targeted to promoting regeneration under these compromised conditions. There is also a concern of biomaterials, which themselves have been associated with infection and inflammation.

Here, we review the biomaterials that are designed for use in compromised patients with inflammation or active infections. We present several examples of each of the groups of biomaterials, taken from our own research and cases that are documented within the literature.

\section{BIOMATERIALS ASSOCIATED WITH UNDESIRED INFLAMMATION AND INFECTION}

\section{Biomaterials and Inflammation}

Biomaterials are essentially foreign to the human body and, as such, have been associated with triggering inflammation and immune reactions. Initial inflammation is necessary for wound

${ }^{1}$ http://www.organdonor.gov/about/data.html healing and occurs when biomaterials are in contact with host tissues. The milder irritation produced includes mild to moderate pain or discomfort, such as itching. Inflammation occurs with a more severe response and presents redness, heat, swelling, pain. This is a defensive response and occurs to some degree with all resorbable materials. Inflammation only becomes a problem if it becomes prolonged (chronic) and increases in severity leading to immunologically mediated events that lead to destruction of the implants or cell/tissue death. Reviews on the inflammatory response to biomaterials are available (Anderson et al., 2008 and Slee et al., 2014) and will not be discussed here.

\section{Biomaterials and Biodevices-Related Infections}

As foreign materials that have been introduced into the body, biomaterials would also be a potential source of infection. Biomaterials made from metals, ceramics, and polymers are now in routine clinical use and have been linked to infection (Buhmann et al., 2016 and Busscher et al., 2012). For example, approximately 60,000 deaths per year have been reported in the USA due to device-related infections from urinary catheters and central venous catheters, and those made from polyurethane have been shown to constitute an entry pathway into body for bacteria (O'Grady et al., 2002). Bacteria will compete with cells to adhere to surface of biomaterials, as many of them have similar mechanism of attachment as cells, except they are better adapted for survival on non-viable surfaces. Common bacterial infections on polymeric biomaterials come from Staphylococcus epidermidis (S. epidermidis) from skin and Staphylococcus aureus (S. aureus), which is often found on metallic biomaterials. Some of these bacteria may be resistant to antibiotics (different surface expression). These have been found on artificial hearts, synthetic vessels, joint replacement implants, fixation devices, IV catheters, urologic devices, and contact lenses (Holzapfel et al., 2013). Ceramics and metals are relatively resistant to infection, but if there are imperfections on the surface or microfractures, pathogens, such as bacteria, can establish a colony (Holzapfel et al., 2013).

A group of aliphatic polymers, such as polyethylene, polytetrafluoroethylene, polypropylene, and also polyvinylidene fluoride, have selective affinity toward endotoxins (Davies, 1999). Thus, they have the potential to facilitate the microenvironment for tissue regeneration by adsorbing the endotoxins. However, due to absence of hydrophilic ionizable groups, they cannot be used directly before further biocompatible functionalization. Charged polymers with effective functional groups can selectively bind and remove endotoxins from the systems. One such example is positively charged acrylic cellulose with DEAE or QAE functional groups that can significantly absorb endotoxins (Hou and Zaniewski, 1990). This could be an important aspect while designing advanced biomaterials for clinical translations.

\section{Extracellular Matrix and Pathogenic Transmission}

More recently, biomaterials from natural sources have gained significant interest as scaffolds for promoting regeneration. In particular, the decellularization of organs and tissues to 
obtain scaffolds composed extracellular matrix (ECM) components have gained considerable popularity (Faulk et al., 2014). Such scaffolds have been shown to be conducive to regeneration. However, these are either derived from human cadaveric sources or from xenogeneic sources. Both sources carry a risk for pathogenic transmission. Xenogeneic scaffolds have an additional risk of inducing allergic or inflammation reactions. Bone allografts are known to transmit several deadly viruses like hepatitis, tuberculosis (TB), and human immunodeficiency virus (HIV-1) (Vincent, 2012). Similarly, corneas have been reported to transmit hepatitis $\mathrm{B}$ virus (HBV), rabies, cytomegalovirus (CMV), Creutzfeldt-Jakob disease (CJD), and herpes simplex virus (HSV), apart from different bacteria and fungi (Lee et al., 2007). Furthermore, heart valves have been shown to transmit TB and HBV (Zou et al., 2004). Skins from seropositive donors were associated with HIV-1 and CMV transmission (Eastlund, 1995). Therefore, critical care and appropriate safety measures, such as rigorous screening, are required during the process of transplanting decellularized organs.

\section{BIOMATERIALS THAT MODULATE INFLAMMATION}

Despite being necessary during the early stages of wound healing, inflammation plays a major role in the rejection of biomaterial implants. Dysregulated and excessive or chronic inflammation has a negative impact on the wound healing processes. Therefore, strategies to modulate excessiveinflammation are needed. Through the use of biomaterials to control the release of anti-inflammatory therapeutics, increased control over inflammation is possible in a range of pathological conditions. However, the choice of biomaterial (natural or synthetic) and its form (solid, hydrogel, or micro/ nanoparticle) is dependent on both the cause and tissue location of inflammation. These considerations also influence the nature of the anti-inflammatory therapeutic that is incorporated into the biomaterial to be delivered. There are two groups of biomaterials: those that possess intrinsic anti-inflammatory properties and those that are designed to incorporate anti-inflammatory agents. Examples of each group are given below.

\section{Biomaterials with Intrinsic Anti-inflammatory Properties}

Some biopolymers, and in particular, polysaccharides, have inherent anti-inflammatory properties. For example, chitosan, a linear polysaccharide composed of randomly distributed $\beta$-(1-4)-linked D-glucosamine and $\mathrm{N}$-acetyl-D-glucosamine derived from crustacean shells, has long been reported to have anti-inflammatory properties. Song et al. studied the anti-inflammatory effects of the chitosan-gelatin hybrid materials cross-linked with genipin. They concluded that the anti-inflammatory effects of genipin could be due to its effect on the NO/iNOS pathway and inhibition of the mRNA expression of COX-2 and IL- 6 within activated macrophages (Song et al., 2011). Chitosan-based materials are believed to be anti-inflammatory based on their ROS scavenging properties (Je and Kim, 2006). Other biopolymers, primarily polysaccharides from plants, such as mushrooms (Elsayed et al.,
2014) and seaweed (Rodrigues et al., 2012 and Park et al., 2011), are being examined for their anti-inflammatory properties. It is possible for these in the future to be tested as biomaterials.

Polyethylene glycol (PEG) and its nano-conjugated derivatives have also been shown to possess anti-inflammatory properties (Dobrovolskaia and McNeil, 2007). For example, PEG has been hybridized by incorporation of peptides, such as GRGDSPG, to form hydrogels with anti-inflammatory properties. GRGDSPG-containing peptides have been reported to protect MIN6 mouse pancreatic islet-derived cells from cytokine-induced cell death when functionalized to encapsulate these cells. These peptide-containing hydrogels in conjunction with the interleukin-1 receptor inhibitory peptide (IL-1RIP) FEWTPGWYQPY-NH2 were particularly effective in protecting the islet cells (Su et al., 2010).

\section{Integrative Anti-inflammatory Materials}

Implantation of tectonic patches made from interpenetrating networks of collagen and 2-methacryloyloxyethyl phosphorylcholine (MPC) into three patients in a small hospital-based study under compassionate use revealed that this material was able to stably restore the integrity of the damaged corneas of patients with chronic ulceration or erosion of the epithelium due to stroma damage, thereby relieving patients from pain, discomfort, and photophobia (Buznyk et al., 2015). MPC has also been shown to have anti-inflammatory properties in other systems. For example, MPC-polymer has been shown to be useful for oral care. It protects from oral infection by preventing the adherence of periodontal pathogen and succeeding inflammatory reaction and, thus, protects gingival epithelium to maintain oral epithelial function (Yumoto et al., 2015).

Hyaluronic acid (HA) hydrogels have been widely used as scaffolds for promoting regeneration because of their reported anti-inflammatory nature (Nakamura et al., 2004; Hirabara et al., 2013). TNF- $\alpha$ antibody-conjugated HA hydrogels have been shown to reduce IL- $1 \beta$ concentration and macrophage infiltration when applied to burn wounds. This, in turn, reduced the thickness of the non-viable tissue (Friedrich et al., 2014). HA-based scaffolds with mesenchymal stem cells completely eliminated the inflammatory process when transplanted in pig models of myocardial infarction (Muscari et al., 2013).

To reduce the foreign body reaction (FBR), plasmid-encoded or virus-encapsulated IL-10 can efficiently downregulate the inflammatory response against collagen scaffolds, when transplanted subcutaneously in rats (Van Putten et al., 2009; Holladay et al., 2012). Combined glycosaminoglycan high sulfated hyaluronan with collagen scaffold reduced the secretion of pro-inflammatory cytokines and increased the anti-inflammatory cytokines, when macrophages were cultured on the implants (Kajahn et al., 2012) in in vitro-mimicked conditions of sterile tissue injury.

\section{Biomaterials Developed as Delivery Systems to Control Inflammation}

Not all biomaterials in clinical use are inherently anti-inflammatory in nature. However, they have been used to deliver a wide variety of therapeutic agents that were developed to control 
inflammation. The need for delivery agents stems from the fact that most therapeutic agents on their own fail to achieve a high enough local concentration to exert their effects. One approach to address this problem is the use of biomaterials as delivery agents and reservoirs for the therapeutic agent(s) and, in particular, provide sustained release of effective concentrations for prolonged periods of time. For example, the incorporation of stromal cell-derived factor- 1 alpha (SDF- $1 \alpha$ ) into PLGA scaffolds reduced inflammation when transplanted into the subcutaneous cavity of Balb/C mice to improve both the tissue response and regenerative potential of tissue engineering scaffolds by reducing the local inflammation. It decreased the number and responses of mast cell near the implants together with reduced expression of IL-1 $\alpha$, IL-6, and TNF- $\alpha$ and increased VEGF expression (Thevenot et al., 2010).

A PLLA scaffold releasing Ibuprofen was shown to reduce IL- 6 and TNF- $\alpha$ expression leading to decreased inflammatory responses and improved muscle regeneration (Yuan et al., 2014). Dexamethasone incorporated hydrogels reduced TNF- $\alpha$ and IL- 6 expression from macrophages that ultimately reduced inflammatory response in lipopolysaccharide-stimulated primary mouse macrophages in vitro (Ito et al., 2007). Gelatin hydrogels incorporating mixed immunosuppressive triptolide-micelles and bone morphogenic protein-2 (BMP-2) downregulated the expression of pro- and anti-inflammatory cytokines, including IL- 6 and IL-10, and reduced local inflammation responses and enhanced bone regeneration in rat model (Ratanavaraporn et al., 2012).

Although a plethora of potential delivery systems have been reported, only a few anti-inflammatory drug delivery materials are currently used in the clinic. One of these is a system for sustained delivery of dexamethasone (Ozurdex, Allergan Inc., Irvine, CA, USA). The implant is introduced into the posterior segment of the patient's eyes with various pathologic conditions, including diabetic macular edema, non-infectious intermediate uveitis, and birdshot chorioretinopathy, and has been shown to exhibit a good safety profile and promising results in edema and inflammation control (Cao et al., 2014; Dugel et al., 2015; Walsh and Reddy, 2016). Further clinical trials are ongoing to confirm these initial results (ClinicalTrials.gov identifier: NCT01801774, NCT02736175, and NCT02547623). ${ }^{2}$

\section{BIOMATERIALS THAT MODULATE INFECTION}

\section{Biomaterials with Intrinsic Anti-infective Properties}

Just like there are biomaterials with innate anti-inflammatory behavior, there are biomaterials that have intrinsic anti-infective properties, and there are those that are effective as carriers of antibacterial and antiviral agents or other bioactives developed to combat infectious agents. There is a wide range of these and only a selected few examples are provided below. Biomaterials containing sulfated groups are known to have anti-infective properties. These include antibacterial as well as antiviral

${ }^{2}$ https://clinicaltrials.gov/ properties. The best-known are the marine-derived sulfated polysaccharides derived from brown seaweeds (Phaeophyceae such as Fucus, Laminaria, and Ascophyllum). These macromolecules include alginates and fucoidans (Berteau and Mulloy, 2003; Marguerite, 2014).

Among the properties attributed to fucoidans is its antiviral activity (Damonte et al., 2004). Fucoidans isolated contain mainly $\mathrm{O}$-sulfated $\alpha$-L-fucosides but they also contain acetyl groups and other types of saccharides and proteins (Morya et al., 2012). Our group had examined the possibility of reproducing the antiviral properties of fucoidans in synthetic mimics and confirmed that the sulfation was essential for activity against viruses, such as Herpes Simplex Virus serotype 1 (HSV-1) (Tengdelius et al., 2014). However, we also found that the activity of synthetic fucoidan was similar to that of other sulfated polysaccharides, such as heparin and dextran sulfate, while non-sulfated control synthetic fucoidans or polyacrylamide did not block viral activity. We, further, showed that synthetic $\mathrm{O}$-sulfated fucoidans blocked HSV-1 activity during the viral adsorption step, reacting with viral particles to prevent their entry into cells (Tengdelius et al., 2014). More recently, we examined the anti-HSV-1 efficacy of another fully synthetic sulfated biomaterial, polystyrene sulfonate [poly(sodium 4-styrenesulfonate) (PSS)]. We developed theranostic contact lenses, i.e., contact lenses that could detect and modulate HSV-1 infection. Here, PSS was used as coatings to effectively provide antiviral activity (Mak et al., 2015).

\section{Nanomaterials with Antimicrobial Properties}

A wide range of nanomaterials, from carbon nanotubes (CNTs) and fullerenes to dendrimers and metal nanoparticles has been shown to have intrinsic anti-infective properties against bacteria, viruses, and other pathogens (reviewed in Rai et al., 2015). Table 1 provides a list of various nanoparticle systems and their reported antimicrobial (antibacterial) activities.

The best-known metallic nanoparticles with antibacterial activity are the silver nanoparticles (AgNPs) and silver in general. These are known for their antibacterial and antiviral properties. Use of silver in medical implants has a long history of medical use. Colloidal silver has been approved for wound treatment since the 1920s and registered as a bactericidal substance since 1954 (Nowack et al., 2011; Reidy et al., 2013). New solutions combine regeneration and antimicrobial effects to allow faster and safer recovery from injury. Silver containing wound dressings include Acticoat ${ }^{\circledR}$, a commercial wound dressing utilizing nanocrystaline silver (Khundkar et al., 2010), Actisorb ${ }^{\circledR}$, which contains a silvernylon cloth, and Calgitrol $\mathrm{Ag}^{\circledR}$ that utilizes silver-alginate (Simon et al., 2016). Silver ions have been shown to have toxicity on cells and also in vivo. However, it has been shown that silver nanoparticles produced as naked particles and coated with collagen or LL-37 peptide have reduced cytotoxicity on human skin epidermal cells compared to ionic silver (Alarcon et al., 2015). However, they were effective against bacteria tested, such as S. aureus (strain ATTC 25923), S. epidermidis (strain Se19), Escherichia coli (strain CFT073), and Pseudomonas aeruginosa (strain PA01). Methicillin-resistant S. epidermidis (MRSE) and 
TABLE 1 | Type of various nanoparticles and their applications in antimicrobial and antiviral treatment.

\begin{tabular}{|c|c|c|}
\hline Type of nanoparticles & Antimicrobial activity & Reference \\
\hline \multicolumn{3}{|l|}{ Metallic nanoparticles } \\
\hline $\mathrm{ZnO}, \mathrm{CuO}, \mathrm{Fe}_{2} \mathrm{O}_{3}$ & E. coli, $P$. aeruginosa, $S$. aureus, $B$. subtilis & Azam et al. (2012) \\
\hline Silver, titanium dioxide, silica dioxide nanoparticles & S. mutans & Besinis et al. (2014) \\
\hline Sliver & E. coli, $P$. aeruginosa, S. aureus & Guzman et al. (2012) \\
\hline Silver (biological) & E. coli, S. aureus, E. faecalis & Barbinta-Patrascu et al. (2014) \\
\hline Silver (biological and chemical) & E. coli, S. aureus & Bawskar et al. (2015) \\
\hline Collagen-AgNP hydrogels & S. aureus, S. epidermidis, E. coli, P. aeruginosa & Alarcon et al. (2015) \\
\hline \multicolumn{3}{|l|}{ Carbon nanotubes (CNTs) } \\
\hline Single/multi-walled CNTs & L. acidophilus, B. adolescentis, E. coli, E. faecalis, S. aureus & Chen et al. (2013) \\
\hline AgNPs decorated CNTs & E. coli, S. aureus & Dinh et al. (2015) \\
\hline Chitosan-CNT hydrogels & S. aureus, E. coli, C. tropicalis & Venkatesan et al. (2014) \\
\hline Gelatin-CNTs & K. pneumoniae, E. coli & Spizzirri et al. (2015) \\
\hline Functionalized fullerenes & E. coli, C. albicans, S. aureus & Mizuno et al. (2011); Tegos et al. (2005) \\
\hline Dendrimers & S. aureus, $P$. aeruginosa, E. coli & Lind et al. (2015) \\
\hline Type of nanoparticles & Antiviral activity & Reference \\
\hline \multicolumn{3}{|l|}{ Silver nanoparticles (AgNPs) } \\
\hline AgNPs & HIV-1 inhibition & Elechiguerra et al. (2005); Gaikwad et al. \\
\hline PVP-stabilized AgNPs & HSV and HPIV & (2013); Hu et al. (2014); Lara et al. (2010) \\
\hline Mercaptoethanesulfonate-capped AgNPs & HSV-1 & Baram-Pinto et al. (2010) \\
\hline AgNPs/chitosan composites & H1N1 influenza & Xiang et al. (2011); Mori et al. (2013) \\
\hline Polysaccharide-coated AgNPs & Tacaribe virus & Speshock et al. (2010) \\
\hline \multicolumn{3}{|l|}{ Gold nanopartices (AuNPs) } \\
\hline Glucose-coated AuNPs & HIV treatment & Chiodo et al. (2014) \\
\hline AuNPs conjugated with peptide triazoles & HIV treatment & Bastian et al. (2015) \\
\hline Sulfated ligands-coated AuNPs & HIV treatment & Di Gianvincenzo et al. (2010) \\
\hline Fluorescein-labeled oligomannoside AuNPs & HIV treatment & Martínez-Avila et al. (2009); Arnáiz et al. (2012) \\
\hline Mercaptobenzoic acid-coated AuNPs & HIV treatment & Bowman et al. (2008) \\
\hline Mercaptoethane sulfonate-capped AuNPs & HSV-1 & Baram-Pinto et al. (2010) \\
\hline Solid lipid nanoparticles (SLN) & Hepatitis B virus (HBV) & Zhang et al. (2008) \\
\hline Quantum rods (QRs) & HIV-1 & Mahajan et al. (2010) \\
\hline
\end{tabular}

methicillin-resistant $S$. aureus (MRSA) have been reported to be successfully inhibited by "NanoSilver" embedded bone cement in an in vitro model with human osteoblasts, whereas similar cement with gentamicin could not able to prevent the infection with such resistant strains (Alt et al., 2004). Within our group, we have developed simple composite collagen-based hydrogels that have included silver nanoparticles with antibacterial properties as corneal implants (Alarcon et al., 2016).

\section{Antiviral Nanosystem}

Nanoparticles and their different composites have also had antiviral activity (Table 1). They have now been shown to interact with the HIV-1 virus in a size-dependent manner possibly through the gp120 subunit of the viral envelope glycoprotein (Di Gianvincenzo et al., 2010; Lara et al., 2010).

Like antibiotics, however, resistance to silver has been found in bacteria. The reports, to date, point to the resistance being plasmid-based, and not all bacteria examined have been shown to harbor these plasmids. Overall, the incidence of silver resistance remains low compared to antibiotic resistance (Griffith et al., 2015).

\section{Composite Biomaterials as Delivery Systems}

Nanoparticles have also been used as carriers for bioactives and antiviral drugs. For example, silver and gold coated with sulfated ligands developed have been shown to exert their anti-HIV activity by inhibiting the binding of HIV gp120 on the host cell receptors at early stage of viral replication (Di Gianvincenzo et al., 2010; Lara et al., 2010). Several studies have evaluated the potential antiviral efficacy of antiviral drug delivery systems against HIV-1 infection (Bowman et al., 2008; Mahajan et al., 2010; Chiodo et al., 2014; Bastian et al., 2015) or HBV, showing promising results in terms of enhanced antiviral potency or efficiency in delivery of the drugs/peptides used. Zhang et al. showed that adefovir dipiroxil (ADV), a nucleotide analog with potent antiviral activity against chronic HBV, loaded in solid lipid NPs significantly lowered HBV DNA levels compared with free ADV (Zhang et al., 2008).

We have previously reported collagen implants containing silica nanoparticles releasing LL37 peptide that has anti-HSV-1 antiviral properties (Lee et al., 2014). Other more sophisticated composite biomaterials have been developed as local antibiotic carriers system that offer regulated release of antibiotics in specific tissues and implant. An example of such biomaterials is $\mathrm{TiO}_{2}-\mathrm{NiFe}_{2} \mathrm{O}_{4}$ nanoparticle system that comprise particles with photocatalytic shells and magnetic cores, to form removable antimicrobial photocatalyst system that can be extracted from the sprayed surface (infected region) after exposure (Rana et al., 2005). Biocompatible, injectable polymeric carriers, e.g., Pluronic ${ }^{\circledR}$ F127 that can respond in situ to physiological stimuli 


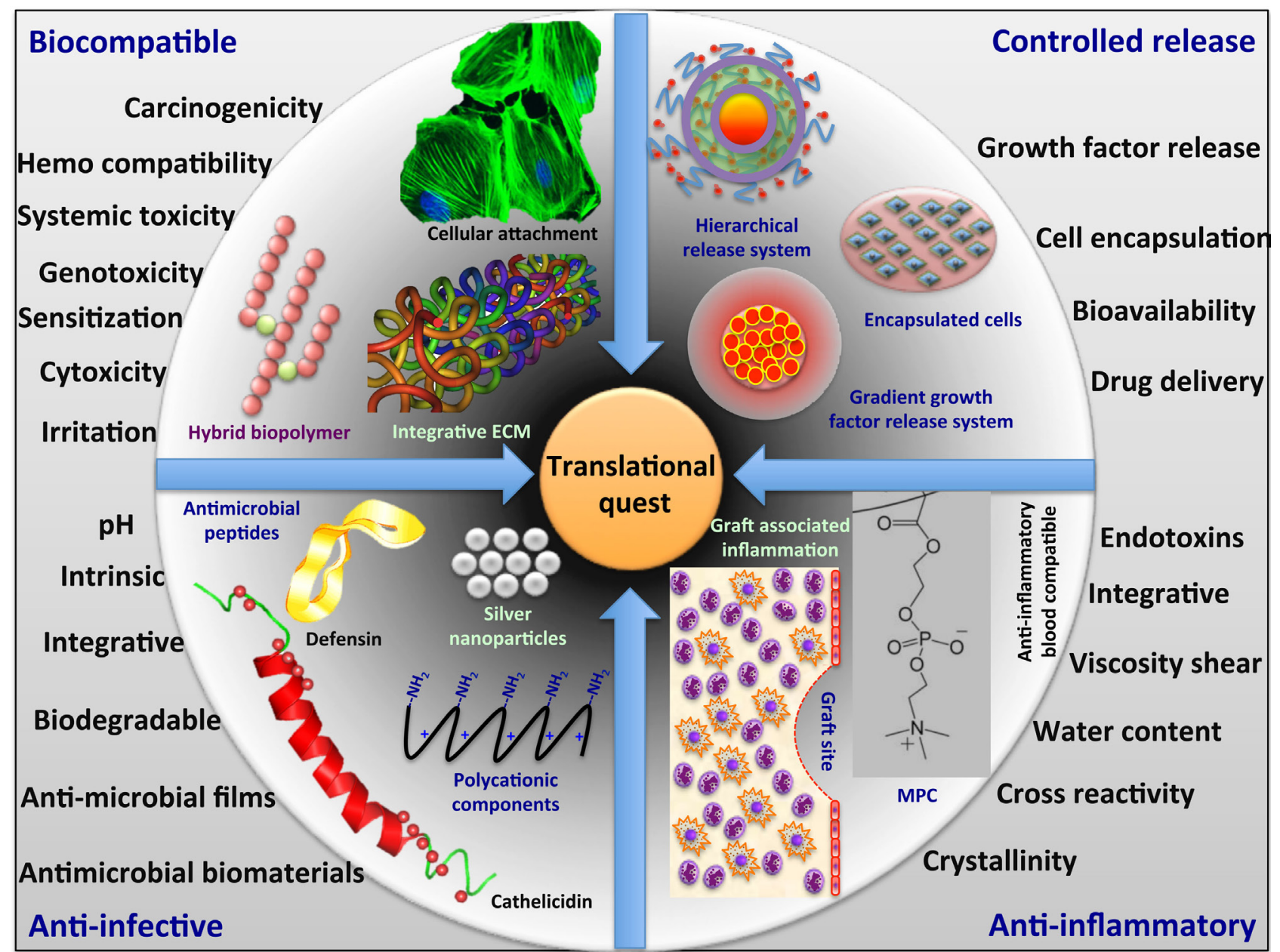

FIGURE 1 | Translational quest for next generation biomaterials.

have also been developed for controlled drug release (Simões et al., 2012). To combat with the increasing concern of antibiotic resistance, composite nanosystems that combine conventional antibiotics with nanoparticles have been reported to successfully inhibit drug resistant microbes compared with antibiotics alone (Campoccia et al., 2010). Several approaches are going on with antibiotic-loaded biomaterials for local infection prophylaxis, and one such example that is available for use in the clinic is poly(D,L-lactide) (PDLLA) coating. The idea is to turn an implant into a drug delivery device. ${ }^{3}$

We have summarized the different functional aspects and the major concern in developing the biomaterials for their successful clinical translation (Figure 1).

${ }^{3}$ www.synthes.com

\section{REFERENCES}

Alarcon, E. I., Udekwu, K. I., Noel, C. W., Gagnon, L. B. P., Taylor, P. K., Vulesevic, B., et al. (2015). Safety and efficacy of composite collagen-silver nanoparticle

\section{CONCLUSION}

In conclusion, biomaterials are now being developed to address issues of infection and inflammation in compromised patients. These include those materials with inherent anti-inflammatory or anti-infective properties as well as materials bioengineered to deliver those properties. Several examples of each have now reached the pre-clinical and clinical evaluation stages and show promising results. However, this area is still in its infancy, and the search for biomaterials and implants that can promote regeneration while addressing localized infection and inflammation continues.

\section{AUTHOR CONTRIBUTIONS}

HP and MG conceptualize the area for this review. MI, JE, GP, and $\mathrm{OB}$ have contributed in their respective sections.

hydrogels as tissue engineering scaffolds. Nanoscale 7, 18789-18798.doi:10.1039/ c5nr03826j

Alarcon, E. I., Vulesevic, B., Argawal, A., Ross, A., Bejjani, P., Podrebarac, J., et al. (2016). Coloured cornea replacements with anti-infective properties: expanding 
the safe use of silver nanoparticles in regenerative medicine. Nanoscale 8, 6484-6489. doi:10.1039/c6nr01339b

Alt, V., Bechert, T., Steinrücke, P., Wagener, M., Seidel, P., Dingeldein, E., et al. (2004). An in vitro assessment of the antibacterial properties and cytotoxicity of nanoparticulate silver bone cement. Biomaterials 25, 4383-4391. doi:10.1016/j. biomaterials.2003.10.078

Anderson, J. M., Rodriguez, A., and Chang, D. T. (2008). Foreign body reaction to biomaterials. Semin. Immunol. 20, 86-100. doi:10.1016/j.smim.2007.11.004 Academic Press

Arnáiz, B., Olga, M., Juan, M. F., and Soledad, P. (2012). Cellular uptake of gold nanoparticles bearing HIV gp120 oligomannosides. Bioconjug. Chem. 23, 814-825. doi:10.1021/bc200663r

Azam, A., Ahmed, A. S., Oves, M., Khan, M. S., Habib, S. S., and Memic, A. (2012). Antimicrobial activity of metal oxide nanoparticles against Gram-positive and Gram-negative bacteria: a comparative study. Int. J. Nanomedicine 7, 6003-6009. doi:10.2147/IJN.S35347

Baram-Pinto, D., Shukla, S., Gedanken, A., and Sarid, R. (2010). Inhibition of HSV-1 attachment, entry, and cell-to-cell spread by functionalized multivalent gold nanoparticles. Small 6, 1044-1050. doi:10.3390/v5061447

Barbinta-Patrascu, M. E., Ungureanu, C., Iordache, S. M., Iordache, A. M., Bunghez, I.-R., Ghiurea, M., et al. (2014). Eco-designed biohybrids based on liposomes, mint-nanosilver and carbon nanotubes for antioxidant and antimicrobial coating. Mater. Sci. Eng. C Mater. Biol. Appl. 39, 177-185. doi:10.1016/j. msec.2014.02.038

Bastian, A. R., Nangarlia, A., Bailey, L. D., Holmes, A., Sundaram, R. V. K., Ang, C., et al. (2015). Mechanism of multivalent nanoparticle encounter with HIV-1 for potency enhancement of peptide triazole virus inactivation. J. Biol. Chem. 290, 529-543. doi:10.1074/jbc.M114.608315

Bawskar, M., Deshmukh, S., Bansod, S., Gade, A., and Rai, M. (2015). Comparative analysis of biosynthesised and chemosynthesised silver nanoparticles with special reference to their antibacterial activity against pathogens. IET Nanobiotechnol. 9, 107-113. doi:10.1049/iet-nbt.2014.0032

Berteau, O., and Mulloy, B. (2003). Sulfated fucans, fresh perspectives: structures, functions, and biological properties of sulfated fucans and an overview of enzymes active toward this class of polysaccharide. Glycobiology 13, 29R-40R. doi:10.1093/glycob/cwg058

Besinis, A., De Peralta, T., and Handy, R. D. (2014). The antibacterial effects of silver, titanium dioxide and silica dioxide nanoparticles compared to the dental disinfectant chlorhexidine on Streptococcus mutans using a suite of bioassays. Nanotoxicology 8, 1-16. doi:10.3109/17435390.2012. 742935

Bowman, M. C., Ballard, T. E., Ackerson, C. J., Feldheim, D. L., Margolis, D. M., and Melander, C. (2008). Inhibition of HIV fusion with multivalent gold nanoparticles. J. Am. Chem. Soc. 130, 6896-6897. doi:10.1021/ja710321g

Buhmann, M. T., Stiefel, P., Maniura-Weber, K., and Ren, Q. (2016). In vitro biofilm models for device-related infections. Trends Biotechnol. doi:10.1016/j. tibtech.2016.05.016

Busscher, H. J., Van Der Mei, H. C., Subbiahdoss, G., Jutte, P. C., Van Den Dungen, J. J., Zaat, S. A., et al. (2012). Biomaterial-associated infection: locating the finish line in the race for the surface. Sci. Transl. Med. 4, 153. doi:10.1126/ scitranslmed. 3004528

Buznyk, O., Pasyechnikova, N., Islam, M. M., Iakymenko, S., Fagerholm, P., and Griffith, M. (2015). Bioengineered corneas grafted as alternatives to human donor corneas in three high-risk patients. Clin. Transl. Sci. 8, 558-562. doi:10.1111/cts.12293

Campoccia, D., Montanaro, L., Speziale, P., and Arciola, C. R. (2010). Antibioticloaded biomaterials and the risks for the spread of antibiotic resistance following their prophylactic and therapeutic clinical use. Biomaterials 31, 6363-6377. doi:10.1016/j.biomaterials.2010.05.005

Cao, J. H., Mulvahill, M., Zhang, L., Joondeph, B. C., and Dacey, M. S. (2014). Dexamethasone intravitreal implant in the treatment of persistent uveitic macular edema in the absence of active inflammation. Ophthalmology 121, 1871-1876. doi:10.1016/j.ophtha.2014.04.012

Chen, H., Wang, B., Gao, D., Guan, M., Zheng, L., Ouyang, H., et al. (2013). Broadspectrum antibacterial activity of carbon nanotubes to human gut bacteria. Small 9, 2735-2746. doi:10.1002/smll.201202792

Chiodo, F., Marco, M., Javier, C., Eloisa, Y., and Soledad, P. (2014). Glycosystems in nanotechnology: gold glyconanoparticles as carrier for anti-HIV prodrugs. Beilstein J. Org. Chem. 10, 1339-1346. doi:10.3762/bjoc.10.136
Damonte, E. B., Matulewicz, M. C., and Cerezo, A. S. (2004). Sulfated seaweed polysaccharides as antiviral agents. Curr. Med. Chem. 11, 2399-2419. doi:10.2174/0929867043364504

Davies, J. R. (1999). From a Biological Product by Contacting Said Biological Product with Cross-Linked Hydrophilic Matrix Comprising a Copolymer of Allyl Dextran and N, N'-Methylene Bisacrylamide. U.S. Patent 5917022.

Di Gianvincenzo, P., Marradi, M., Martínez-Ávila, O. M., Bedoya, L. M., Alcamí, J., and Penadés, S. (2010). Gold nanoparticles capped with sulfate-ended ligands as anti-HIV agents. Bioorg. Med. Chem. Lett. 20, 2718-2721. doi:10.1016/j. bmcl.2010.03.079

Dinh, N. X., Quy, N. V., Huy, T. Q., and Le, A.-T. (2015). Decoration of silver nanoparticles on multiwalled carbon nanotubes: antibacterial mechanism and ultrastructural analysis. J. Nanomater. 2015, 11. doi:10.1155/2015/814379

Dobrovolskaia, M. A., and McNeil, S. E. (2007). Immunological properties of engineered nanomaterials. Nat. Nanotechnol. 2, 469-478. doi:10.1038/ nnano.2007.223

Dugel, P. U., Bandello, F., and Loewenstein, A. (2015). Dexamethasone intravitreal implant in the treatment of diabetic macular edema. Clin. Ophthalmol. 9, 1321. doi:10.2147/OPTH.S79948

Eastlund, T. (1995). Infectious disease transmission through cell, tissue, and organ transplantation: reducing the risk through donor selection. Cell Transplant. 4, 455-477. doi:10.1016/0963-6897(95)00035-V

Elechiguerra, J. L., Burt, J. L., Morones, J. R., Camacho-Bragado, A., Gao, X., Lara, H. H., et al. (2005). Interaction of silver nanoparticles with HIV-1. J. Nanobiotechnology 3, 1-10. doi:10.1186/1477-3155-3-6

Elsayed, E. A., El Enshasy, H., Wadaan, M. A., and Aziz, R. (2014). Mushrooms: a potential natural source of anti-inflammatory compounds for medical applications. Mediators Inflamm. 805841. doi:10.1155/2014/805841

Faulk, D. M., Johnson, S. A., Zhang, L., and Badylak, S. F. (2014). Role of the extracellular matrix in whole organ engineering. J. Cell Physiol. 229, 984-989. doi:10.1002/jcp. 24532

Friedrich, E. E., Sun, L. T., Natesan, S., Zamora, D. O., Christy, R. J., and Washburn, N. R. (2014). Effects of hyaluronic acid conjugation on anti-TNF- $\alpha$ inhibition of inflammation in burns. J. Biomed. Mater. Res. A 102, 1527-1536. doi:10.1002/ jbm.a.34829

Gaikwad, S., Ingle, A., Gade, A., Rai, M., Falanga, A., Incoronato, N., et al. (2013). Antiviral activity of mycosynthesized silver nanoparticles against herpes simplex virus and human parainfluenza virus type 3. Int. J. Nanomedicine 8, 4303. doi:10.2147/IJN.S50070

Griffith, M., Udekwu, K. I., Gkotzis, S., Mah, T. F., and Alarcon, E. I. (2015). "Anti-microbial and anti-infective activities of silver," in Silver Nanoparticle Applications: In the Fabrication and Design of Medical and Biosensing Devices, eds E. I.Alarcon, M.Griffith, and K. I.Udekwu (Switzerland: Springer), 127-146. doi:10.1007/978-3-319-11262-6_6

Guzman, M., Dille, J., and Godet, S. (2012). Synthesis and antibacterial activity of silver nanoparticles against gram-positive and gram-negative bacteria. Nanomedicine 8, 37-45. doi:10.1016/j.nano.2011.05.007

Hirabara, S., Kojima, T., Takahashi, N., Hanabayashi, M., and Ishiguro, N. (2013). Hyaluronan inhibits TLR-4 dependent cathepsin $\mathrm{K}$ and matrix metalloproteinase 1 expression in human fibroblasts. Biochem. Biophys. Res. Commun. 430, 519-522. doi:10.1016/j.bbrc.2012.12.003

Holladay, C. A., Duffy, A. M., Chen, X., Sefton, M. V., O'Brien, T. D., and Pandit, A. S. (2012). Recovery of cardiac function mediated by MSC and interleukin-10 plasmid functionalised scaffold. Biomaterials 33, 1303-1314. doi:10.1016/j.biomaterials.2011.10.019

Holmes, K. V. (2003). SARS-associated coronavirus. N. Engl. J. Med. 348, 1948-1951. doi:10.1056/NEJMp030078

Holzapfel, B. M., Reichert, J. C., Schantz, J. T., Gbureck, U., Rackwitz, L., Nöth, U., et al. (2013). How smart do biomaterials need to be? A translational science and clinical point of view. Adv. Drug Deliv. Rev. 65, 581-603. doi:10.1016/j. addr.2012.07.009

Hou, K. C., and Zaniewski, R. (1990). Endotoxin removal by anion-exchange polymeric matrix. Biotechnol. Appl. Biochem. 12, 315-324. doi:10.1111/ j.1470-8744.1990.tb00103.x

Hu, R. L., Li, S. R., Kong, F. J., Hou, R. J., Guan, X. L., and Guo, F. (2014). Inhibition effect of silver nanoparticles on herpes simplex virus 2. Genet. Mol. Res. 13, 7022-7028. doi:10.4238/2014.March.19.2

Ito, T., Fraser, I. P., Yeo, Y., Highley, C. B., Bellas, E., and Kohane, D. S. (2007). Anti-inflammatory function of an in situ cross-linkable conjugate hydrogel of 
hyaluronic acid and dexamethasone. Biomaterials 28, 1778-1786. doi:10.1016/j. biomaterials.2006.12.012

Je, J. Y., and Kim, S. K. (2006). Reactive oxygen species scavenging activity of aminoderivatized chitosan with different degree of deacetylation. Bioorg. Med. Chem. 14, 5989-5994. doi:10.1016/j.bmc.2006.05.016

Kajahn, J., Franz, S., Rueckert, E., Forstreuter, I., Hintze, V., Moeller, S., et al. (2012). Artificial extracellular matrices composed of collagen I and high sulfated hyaluronan modulate monocyte to macrophage differentiation under conditions of sterile inflammation. Biomaterials 2, 226-273. doi:10.4161/ biom. 22855

Khundkar, R., Malic, C., and Burge, T. (2010). Use of Acticoat dressings in burns: what is the evidence? Burns 36, 751-758. doi:10.1016/j.burns.2009.04.008

Lara, H. H., Ayala-Nuñez, N. V., Ixtepan-Turrent, L., and Rodriguez-Padilla, C. (2010). Mode of antiviral action of silver nanoparticles against HIV-1. J. Nanobiotechnology 8, 1-8. doi:10.1186/1477-3155-8-1

Lee, C. J., Buznyk, O., Kuffova, L., Rajendran, V., Forrester, J. V., Phopase, J., et al. (2014). Cathelicidin LL-37 and HSV-1 corneal infection: peptide versus gene therapy. Transl. Vis. Sci. Technol. 3, 4-4. doi:10.1167/tvst.3.3.4

Lee, E. H., Ferguson, D., Jernigan, D., Greenwald, M., Coté, T., Bos, J. E., et al. (2007). Invasive group-A streptococcal infection in an allograft recipient: a case report. J. Bone Joint Surg. Am. 89, 2044-2047. doi:10.2106/JBJS.F.01594

Lind, T. K., Polcyn, P., Zielinska, P., Cárdenas, M., and Urbanczyk-Lipkowska, Z. (2015). On the antimicrobial activity of various peptide-based dendrimers of similar architecture. Molecules 20, 738-753. doi:10.3390/molecules20010738

Mahajan, S. D., Roy, I., Gaixia, X., Ken-Tye, Y., Hong, D., Ravikumar, A., et al. (2010). Enhancing the delivery of anti retroviral drug 'Saquinavir' across the blood brain barrier using nanoparticles. Curr. HIV Res. 8, 396-404. doi:10.2174/157016210791330356

Mak, W. C., Cheung, K. Y., Orban, J., Lee, C. J., Turner, A. P., and Griffith, M. (2015). Surface-engineered contact lens as an advanced theranostic platform for modulation and detection of viral infection. ACS Appl. Mater. Interfaces 7, 25487-25494. doi:10.1021/acsami.5b08644

Marguerite, R. (2014). Biomaterials based on a natural polysaccharide: alginate. TIP 17, 92-96. doi:10.1016/S1405-888X(14)70322-5

Martínez-Avila, O., Hijazi, K., Marradi, M., Clavel, C., Campion, C., Kelly, C., et al. (2009). Gold manno-glyconanoparticles: multivalent systems to block HIV-1 gp120 binding to the lectin DC-SIGN. Chemistry 15, 9874-9888. doi:10.1002/ chem. 200900923

Mizuno, K., Zhiyentayev, T., Huang, L., Khalil, S., Nasim, F., Tegos, G. P., et al. (2011). Antimicrobial photodynamic therapy with functionalized fullerenes: quantitative structure-activity relationships. J. Nanomed. Nanotechnol. 2, 1-9. doi:10.4172/2157-7439.1000109

Mori, Y., Ono, T., Miyahira, Y., Nguyen, V. Q., Matsui, T., and Ishihara, M. (2013). Antiviral activity of silver nanoparticle/chitosan composites against H1N1 influenza A virus. Nanoscale Res. Lett. 8, 93. doi:10.1186/1556-276X-8-93

Morya, V. K., Kim, J., and Kim, E. K. (2012). Algal fucoidan: structural and size-dependent bioactivities and their perspectives. Appl. Microbiol. Biotechnol. 93, 71-82. doi:10.1007/s00253-011-3666-8

Muscari, C., Bonafè, F., Martin-Suarez, S., Valgimigli, S., Valente, S., Fiumana, E., et al. (2013). Restored perfusion and reduced inflammation in the infarcted heart after grafting stem cells with a hyaluronan-based scaffold. J. Cell. Mol. Med. 17, 518-530. doi:10.1111/jcmm.12039

Nakamura, K., Yokohama, S., Yoneda, M., Okamoto, S., Tamaki, Y., Ito, T., et al. (2004). High, but not low, molecular weight hyaluronan prevents T-cell-mediated liver injury by reducing proinflammatory cytokines in mice. J. Gastroenterol. 39, 346-354. doi:10.1007/s00535-003-1301-x

Nowack, B., Krug, H. F., and Height, M. (2011). 120 years of nanosilver history: implications for policy makers. Environ. Sci. Technol. 45, 1177-1183. doi:10.1021/es103316q

O’Grady, N. P., Alexander, M., Dellinger, E. P., Gerberding, J. L., Heard, S. O., Maki, D. G., et al. (2002). Guidelines for the prevention of intravascular catheterrelated infections. Clin. Infect. Dis. 35, 1281-1307. doi:10.1086/344188

Park, H. Y., Han, M. H., Park, C., Jin, C. Y., Kim, G. Y., Choi, I. W., et al. (2011). Anti-inflammatory effects of fucoidan through inhibition of NF-kB, MAPK and Akt activation in lipopolysaccharide-induced BV2 microglia cells. Food Chem. Toxicol. 49, 1745-1752. doi:10.1016/j.fct.2011.04.020

Rai, M., Ingle, A. P., Gaikwad, S., Gupta, I., Gade, A., and Silvério da Silva, S. (2015). Nanotechnology based anti-infectives to fight microbial intrusions. J. Appl. Microbiol. 120, 527-542. doi:10.1111/jam.13010
Rana, S., Rawat, J., and Misra, R. D. K. (2005). Anti-microbial active composite nanoparticles with magnetic core and photocatalytic shell: $\mathrm{TiO}_{2}-\mathrm{NiFe}_{2} \mathrm{O}_{4}$ biomaterial system. Acta Biomater. 1, 691-703. doi:10.1016/j.actbio.2005. 07.007

Ratanavaraporn, J., Furuya, H., and Tabata, Y. (2012). Local suppression of proinflammatory cytokines and the effects in BMP-2-induced bone regeneration. Biomaterials 33, 304-316. doi:10.1016/j.biomaterials.2011.09.050

Reidy, B., Haase, A., Luch, A., Dawson, K., and Lynch, I. (2013). Mechanisms of silver nanoparticle release, transformation and toxicity: a critical review of current knowledge and recommendations for future studies and applications. Materials 6, 2295-2350. doi:10.3390/ma6062295

Rodrigues, J. A., de SO Vanderlei, E., Silva, L. M., de Araújo, I. W., de Queiroz, I. N., de Paula, G. A., et al. (2012). Antinociceptive and anti-inflammatory activities of a sulfated polysaccharide isolated from the green seaweed Caulerpa cupressoides. Pharmacol. Rep. 64, 282-292. doi:10.1016/S1734-1140(12)70766-1

Simões, S. M. N., Veiga, F., Torres-Labandeira, J. J., Ribeiro, A. C. F., SandezMacho, M. I., Concheiro, A., et al. (2012). Syringeable Pluronic- $\alpha$-cyclodextrin supramolecular gels for sustained delivery of vancomycin. Eur. J. Pharm. Biopharm. 80, 103-112. doi:10.1016/j.ejpb.2011.09.017

Simon, S., Phung, P. L., and Silver, G. (2016). Silver as biocides in burn and wound dressings and bacterial resistance to silver compounds. J. Ind. Microbiol. Biotechnol. 33, 627-634. doi:10.1007/s10295-006-0139-7

Slee, J. B., Christian, A. J., Levy, R. J., and Stachelek, S. J. (2014). Addressing the inflammatory response to clinically relevant polymers by manipulating the host response using ITIM domain-containing receptors. Polymers (Basel) 6 , 2526-2551. doi:10.3390/polym6102526

Song, Y. F., Ding, S. S., Cui, Y. L., Wang, Q. S., Ye, L., and Zhang, Y. (2011). The anti-inflammatory effects of biomaterials cross-linked with Genipin. Adv. Mat. Res. 282, 412-416. doi:10.4028/www.scientific.net/AMR.282-283.412

Speshock, J. L., Murdock, R. C., Braydich-Stolle, L. K., Schrand, A. M., and Hussain, S. M. (2010). Interaction of silver nanoparticles with Tacaribe virus. J. Nanobiotechnology 8, 19. doi:10.1186/1477-3155-8-19

Spizzirri, U. G., Hampel, S., Cirillo, G., Mauro, M. V., Vittorio, O., Cavalcanti, P., et al. (2015). Functional gelatin-carbon nanotubes nanohybrids with enhanced antibacterial activity. Int. J. Polym. Mater. Polym. Biomater. 64, 439-447. doi:10.1080/00914037.2014.958833

Stock, U. A., and Vacanti, J. P. (2001). Tissue engineering: current state and prospects. Annu. Rev. Med. 52, 443-451. doi:10.1146/annurev.med.52.1.443

Su, J., Hu, B. H., Lowe, W. L., Kaufman, D. B., and Messersmith, P. B. (2010). Anti-inflammatory peptide-functionalized hydrogels for insulin-secreting cell encapsulation. Biomaterials 31, 308-314. doi:10.1016/j.biomaterials.2009. 09.045

Tegos, G. P., Demidova, T. N., Arcila-Lopez, D., Lee, H., Wharton, T., Gali, H., et al. (2005). Cationic fullerenes are effective and selective antimicrobial photosensitizers. Chem. Biol. 12, 1127-1135. doi:10.1016/j.chembiol.2005.08.014

Tengdelius, M., Lee, C. J., Grenegård, M., Griffith, M., Påhlsson, P., and Konradsson, P. (2014). Synthesis and biological evaluation of fucoidan-mimetic glycopolymers through cyanoxyl-mediated free-radical polymerization. Biomacromolecules 15, 2359-2368. doi:10.1021/bm5002312

Thevenot, P. T., Nair, A. M., Shen, J., Lotfi, P., Ko, C. Y., and Tang, L. (2010). The effect of incorporation of SDF-1 $\alpha$ into PLGA scaffolds on stem cell recruitment and the inflammatory response. Biomaterials 31, 3997-4008. doi:10.1016/j. biomaterials.2010.01.144

Van Putten, S. M., Wübben, M., Hennink, W. E., Van Luyn, M. J. A., and Harmsen, M. C. (2009). The downmodulation of the foreign body reaction by cytomegalovirus encoded interleukin-10. Biomaterials 30, 730-735. doi:10.1016/j. biomaterials.2008.10.043

Venkatesan, J., Jayakumar, R., Mohandas, A., Bhatnagar, I., and Kim, S.-K. (2014). Antimicrobial activity of chitosan-carbon nanotube hydrogels. Materials 7, 3946-3955. doi:10.3390/ma7053946

Vincent, Y. N. (2012). Risk of disease transmission with bone allograft. Orthopedics 35, 679-681. doi:10.3928/01477447-20120725-04

Walsh, J., and Reddy, A. K. (2016). Intravitreal dexamethasone implantation for birdshot chorioretinopathy. Retin. Cases Brief Rep. doi:10.1097/ ICB.0000000000000287

Wang, S., Quang Le, T., Chida, J., Cisse, Y., Yano, M., and Kido, H. (2010). Mechanisms of matrix metalloproteinase- 9 upregulation and tissue destruction in various organs in influenza A virus infection. J. Med. Invest. 57, 26-34. doi:10.2152/jmi.57.26 
Xiang, D. X., Chen, Q., Pang, L., and Zheng, C. L. (2011). Inhibitory effects of silver nanoparticles on H1N1 influenza A virus in vitro. J. Virol. Methods 178, 137-142. doi:10.1016/j.jviromet.2011.09.003

Yuan, Z., Zhao, J., Zhu, W., Yang, Z., Li, B., Yang, H., et al. (2014). Ibuprofen-loaded electrospun fibrous scaffold doped with sodium bicarbonate for responsively inhibiting inflammation and promoting muscle wound healing in vivo. Biomater. Sci. 2, 502-511. doi:10.1039/C3BM60198F

Yumoto, H., Hirota, K., Hirao, K., Miyazaki, T., Yamamoto, N., Miyamoto, K., et al. (2015). Anti-inflammatory and protective effects of 2-methacryloyloxyethyl phosphorylcholine polymer on oral epithelial cells. J. Biomed. Mater. Res. A 103, 555-563. doi:10.1002/jbm.a.35201

Zhang, X., Jing, M., Min-wei, L., Sai-ping, J., Fu-qiang, H., and Yong-zhong, D. (2008). Solid lipid nanoparticles loading adefovir dipivoxil for antiviral therapy. J. Zhejiang Univ. Sci. B 9, 506-510. doi:10.1631/jzus.B0820047
Zou, S., Dodd, R. Y., Stramer, S. L., and Strong, D. M. (2004). Probability of viremia with HBV, HCV, HIV, and HTLV among tissue donors in the United States. N. Engl. J. Med. 351, 751-759. doi:10.1056/NEJMoa032510

Conflict of Interest Statement: The authors declare that the research was conducted in the absence of any commercial or financial relationships that could be construed as a potential conflict of interest.

Copyright (C) 2016 Griffith, Islam, Edin, Papapavlou, Buznyk and Patra. This is an open-access article distributed under the terms of the Creative Commons Attribution License (CC BY). The use, distribution or reproduction in other forums is permitted, provided the original author(s) or licensor are credited and that the original publication in this journal is cited, in accordance with accepted academic practice. No use, distribution or reproduction is permitted which does not comply with these terms. 